\title{
HIBRIDEZ Y TRADICIÓN EN LA CRÓNICA LATINOAMERICANA CONTEMPORÁNEA. LOS TEXTOS DE RAFAEL GUMUCIO ${ }^{1}$
}

\author{
POR \\ Patricia Poblete Alday \\ Universidad Academia de Humanismo Cristiano (Chile)
}

\section{LA EMERGENCIA DE LA CRÓNICA EN LA ACTUALIDAD}

Desde la última década del siglo pasado, la crónica ha proliferado de forma notable en nuestro continente. Esta importancia creciente se ha visto reflejada en iniciativas como la Fundación Nuevo Periodismo Iberoamericano, creada por Gabriel García Márquez en Cartagena de Indias, Colombia, en 1994, y que tiene como misión general "estimular las vocaciones, la ética y la buena narración en el periodismo"; en la creación de revistas que dan espacio al periodismo narrativo de autor-como las colombianas $E l$ Malpensante, Gatopardo y SoHo; la peruana Etiqueta Negra; la boliviana Pie izquierdo; las argentinas Hecho en Buenos Aires y Lamujerdemivida, etc.-; en la publicación de antologías a nivel continental, como Enviados especiales. Antología del nuevo periodismo latinoamericano (México, 2003); Lo mejor de Gatopardo (Colombia, 2005); Lo mejor del periodismo en América Latina (México, 2006); SoHo Crónicas (Colombia, 2008); Crónicas de otro planeta (México, 2009); Domadores de historias. Conversaciones con grandes cronistas de América Latina (Santiago de Chile, 2011) y las más recientes, Antología de crónica latinoamericana actual (España, 2012), Mejor que ficción. Crónicas ejemplares (Barcelona, 2012), y Sam no es mi tío. Veinticuatro crónicas migrantes y un sueño americano (EE.UU., 2012).

La revista colombiana Cambio daba cuenta de este fenómeno en su edición del 5 de agosto de 2009, citando a Mario Jursich, director de la revista El Malpensante: "Si se hablara de un nuevo boom latinoamericano, no sería en el campo de la literatura sino de la crónica". Entre los factores citados en dicha nota para explicar este repunte, están la existencia de una larga tradición narrativa; la ausencia hoy de fenómenos literarios de proporciones, como fue el Boom en los 60; la aparición de revistas que usan la crónica como materia prima, y el impulso de las editoriales. De hecho, estas últimas han abierto

\footnotetext{
1 Parte de la investigación realizada bajo los proyectos Fondecyt $\mathrm{N}^{\circ} 11110202$, del cual fui investigadora responsable y Fondecyt $\mathrm{N}^{\circ} 1140222$, del cual soy coinvestigadora.
} 
sellos especiales o colecciones para acoger la crónica: Santillana las publica bajo el sello Aguilar; Random House lo hace en el sello Debate, y Anagrama tiene la colección Crónicas. Asimismo, la editorial Planeta otorga desde 2006 el Premio de Crónica Planeta/ Seix Barral en conjunto con la Fundación Nuevo Periodismo Iberoamericano.

En Chile, este auge de la crónica se evidencia en hechos como la instauración del Premio Periodismo de Excelencia de la Universidad Alberto Hurtado, en 2003; y en la publicación de antologías como Dios es chileno (Planeta, 2008); Periodismo en el límite (Uqbar, 2008) o Historias de una mujer bomba y otras crónicas de América Latina (Uqbar, 2009). En su edición 197, la revista Capital le dedicó una nota a la emergencia de la crónica en Chile, donde se señala que "[a]lgunos de los mejores libros publicados en el último tiempo no son novelas ni cuentos ni ensayos, sino crónicas". Allí se destaca el trabajo de Alberto Fuguet, Álvaro Bisama, Rafael Gumucio, Francisco Mouat y Roberto Merino. En un artículo editorial del diario La Tercera, el crítico Matías Rivas pondera, igualmente, a Fuguet y Merino, pero agrega además a Pedro Lemebel como una pluma insoslayable en el actual panorama chileno de la crónica.

Entre las razones de este auge podemos considerar la adecuación de la crónica, un texto breve que se lee con rapidez, a las exigencias de un lector/consumidor promedio que cada vez tiene menos tiempo para la lectura, o que busca satisfacción intelectual sin demasiado esfuerzo, o que vuelve a cuestionarse el asunto de la identidad en una época de cambios veloces e incertezas profundas. Podemos considerar también la necesidad del mercado editorial de generar nuevas 'líneas de productos' literarios luego del declive de la Nueva Narrativa chilena, o la vuelta de los escritores hacia los fértiles campos de la realidad, tal y como argüía Tom Wolfe. Más allá de los factores que inciden en este fenómeno, lo relevante es integrar esos antecedentes en una perspectiva móvil, lo suficientemente cercana como para identificar la anatomía de la crónica, pero también con la distancia suficiente para comprenderla como un texto que encarna una hibridez de géneros y oficios, a la vez que establece un diálogo directo con la sociedad que la recibe y posibilita.

\section{GÉNERO Y EVOLUCIÓN}

El consenso que existe al considerar la crónica como un género híbrido [Martínez Albertos 360-361; Chillón 77-181, 185-392; Hernando Cuadrado 21; Rotker 24-27, 123-135; entre otros], se reduce drásticamente a la hora de dilucidar si se trata de una hibridez entre distintos formatos periodísticos -informativo, interpretativo, opinión[Martín Vivaldi 65-67, 123-144, 247-251; Gutiérrez Palacio 99; Vilamor 52-54, 341; Grijelmo 482-484]; entre periodismo e historia (White, "Texto historiográfico" 9-34; Mignolo, "Metatexto" 361,387; Matute 711-722], o entre periodismo y literatura [Borrat 122-123; Aguilera 13-25; Martínez Vallvey 112-113; Chillón 77-181; Monsiváis 56-58; Yanes Mesa].

Revista Iberoamericana, Vol. LXXXII, Núm. 254, Enero-Marzo 2016, $185-198$ ISSN 0034-9631 (Impreso)

ISSN 2154-4794 (Electrónico) 
En Chile, si bien la crónica es una forma textual amplia e históricamente asentada, ${ }^{2}$ su estudio en el ámbito académico es muy reciente y tangencial. Leonidas Morales señala que recién en la década de 1990 se comienza a desarrollar dentro del país el interés teórico y crítico por los géneros de no ficción (57-58). Antes de eso, los estudios realizados tienden a focalizarse en la crónica de tipo informativo, y valorándola siempre como un elemento funcional al periódico del cual forma parte. En esta línea, Ossandón y Santa Cruz identifican cuatro estrategias de acercamiento: los estudios que realizan un inventario de las publicaciones periódicas; los que buscan narrar las vicisitudes de la prensa nacional, utilizando un método descriptivo y empírico a la vez; los que, orientados por una pretensión histórica y analítica, proponen categorías o sistemas de clasificación; y aquellos que buscan reconstruir tramas comunicacionales globales, desde una perspectiva que combina la mirada histórica con la pregunta por el desarrollo de los procesos de modernización y cambio en Chile (Ossandón y Santa Cruz 9-13). Ninguno de ellos, sin embargo, ahonda en la especificidad textual de una crónica que se sitúa entre lo periodístico y lo literario. ${ }^{3}$

Más allá de la discusión sobre su genealogía impura, lo incuestionable es que, antes de cualquier categorización, la crónica es un género ${ }^{4}$ o práctica discursiva que existe con anterioridad al nacimiento del periodismo. Desde el Descubrimiento, ha tenido una importancia decisiva en nuestro continente: primero como documento testimonial que tuvo la doble función de describir las maravillas de las nuevas tierras, y acreditar el provecho de la empresa de Colón; luego como relato épico de las gestas de conquista; más tarde como inventario de la organización de las colonias, y después, como suerte de archivo fundacional de las flamantes naciones. En todas estas etapas, la función más importante y definitoria de la crónica fue la de referir una realidad vivida u observada, y en ese sentido, se la consideró primero una prueba de autenticidad (el 'yo lo vi', como

2 Por mencionar sólo a los más renombrados cronistas: José Joaquín Vallejos (Jotabeche), Joaquín Edwards Bello, Daniel de la Vega, Tito Mundt, Jenaro Prieto, Alberto Romero, Vicente Grez, Vicente Pérez Rosales, Guillermo Feliú Cruz, Horacio Serrano, Manuel Rojas, Alfonso Calderón, José Donoso, Jorge Edwards, Enrique Lafourcade. Incluso Neruda cultivó la crónica: en 1927 el diario La Nación publicó sus crónicas sobre su viaje a Oriente; Las vidas del poeta, crónicas autobiográficas, aparecieron en la revista brasilera O Cruceiro Internacional, en 1962; y entre 1968-1979, la revista Ercilla publicó las Reflexiones desde Isla Negra.

3 Ossandón realiza un análisis de la crónica periodística-literaria pero acotada a la prensa chilena de fin de siglo XIX, y siempre en función de caracterizar al periódico que la contiene. Además, la condición de soporte discursivo y material de este último es subordinada aquí a su función de actor social. El crepúsculo de los sabios sigue esta metodología.

4 En virtud de esa misma hibridez, al hablar de crónica la consideraremos un género en el sentido común del término, esto es, como un tipo relativamente estable de enunciado, sometido a cambios históricos; que genera un horizonte de expectativas en los lectores a la vez que un modelo de escritura para los autores (ver Todorov, "El origen de los géneros" 39).

Revista Iberoamericana, Vol. LXXXII, Núm. 254, Enero-Marzo 2016, 185-198 ISSN 0034-9631 (Impreso)

ISSN 2154-4794 (Electrónico) 
evidencia de la existencia de algo), y luego como un intento por ordenar el espacio de representación (González Echevarría 48-57).

Con el advenimiento de la Modernidad (Paz; Ramos) -aquel estadio en el que la sociedad se transforma siguiendo el ritmo del desarrollo económico y bajo cuyo alero, como es sabido, surge el periodismo- y del Modernismo, la crónica se tornó espacio de resistencia para el letrado, a la vez que su forma de ganarse el sustento. Es la época del flâneur que vaga por la ciudad y narra en sus textos la experiencia del sujeto en medio de un mundo que cambia; el choque entre una subjetividad romántica, y un entorno hostil y depredador. Más allá del resentimiento que genera en el poeta su forzado solapamiento con la figura del periodista, ${ }^{5}$ este sincretismo permitió la libre circulación del literato por distintos espacios, textos y campos culturales, a la vez que generó una mezcla de técnicas y perspectivas que no podrían sino ir en beneficio del texto: velocidad, novedad, impacto, rareza, suspenso; los acercamientos bruscos de elementos disímiles, la renovación permanente, las audacias temáticas, el registro de los matices, la mezcla de sensaciones (Rama). Los procesos de industrialización y urbanización fueron abriendo más espacio para el ocio, a la vez que la ampliación de la educación a sectores antes marginados generó nuevos lectores. La crónica, entonces, se vuelve el lugar de las variedades, de los hechos curiosos pero sin la relevancia suficiente como para aparecer en las secciones 'serias' del periódico; la crónica, desde aquí, es considerada una “suerte de arqueología del presente que se dedica a los hechos menudos y cuyo interés central no es informar sino divertir" (Rotker 123).

En este contexto, y con estos antecedentes, al plantear que el periodismo debía dar cuenta de "la sociedad, el fresco social, las costumbres y las éticas, todo el conjunto de cómo vivimos ahora" (Wolfe 47), el Nuevo Periodismo estadounidense no estaba proponiendo nada nuevo. El real aporte de Tom Wolfe -principal ideólogo y publicista de esta práctica- fue identificar las estrategias escriturales en las que el periodismo confluía con la literatura (detalles simbólicos, escenificación, diálogo, punto de vista en tercera persona) y, al generar una moda en torno a este fenómeno, dar un nuevo impulso a la crónica, que desde entonces adquiere el complemento 'de autor' para diferenciarla de la simple crónica informativa. En América Latina, este fenómeno cristalizó sobre todo en el llamado 'periodismo comprometido', esto es, aquél que denunció los abusos del poder político y las contradicciones del desarrollo, preferentemente utilizando el formato novelado (la non fiction novel), entre los 60 y los $90 .{ }^{6}$

5 En Chile, esta dualidad se pudo ver notablemente encarnada en Guillermo Blest Gana, quien la lamentaba así en el segundo número de El Correo Literario: “¡Ay, si el ministro decreta! / ¡Ay, si algún prójimo chista! / Mató al poeta / El periodista"; "Y en esta existencia mixta / No sé quien vive o vegeta / Si el periodista, / O si el poeta" (citado en Ossandón, El crepúsculo 71).

6 Por mencionar sólo algunas de las publicaciones más relevantes en este ámbito, a nivel latinoamericano: Operación Masacre (Rodolfo Walsh, 1957), La noche de Tlalelolco (Elena Poniatowska, 1971), La

Revista Iberoamericana, Vol. LXXXII, Núm. 254, Enero-Marzo 2016, $185-198$ ISSN 0034-9631 (Impreso)

ISSN 2154-4794 (Electrónico) 
Hoy, el problema que nos planteamos respecto a la falta de estudios sobre la crónica contemporánea debe situarse en el contexto de unas sociedades que son distintas a las que acogieron y posibilitaron los textos modernistas o los cuadros de costumbres coloniales. Se hace necesario, entonces, proponer un enfoque que no se quede en la mera descripción de la anatomía de la crónica, ni en la identificación del origen de sus componentes (criterios que son periodísticos, técnicas que provienen de la literatura, etc.), sino que, desde allí, establezca una relación entre estos elementos y el contexto en el cual son generados y recibidos. En este sentido, los cambios operados desde la globalización y las nuevas tecnologías, nos obligan tanto a re-pensar la función de la crónica y del cronista en nuestras sociedades latinoamericanas, como a analizar las transformaciones observadas en el propio tejido textual.

\section{Las crónicas de Rafael Gumucio}

Los textos del chileno Rafael Gumucio (1970) resultan particularmente atractivos para cuestionarnos por las marcas de identidad de este género en la actualidad, cuya piedrangular parece ser, como ya indicamos, la consabida y sin embargo poco analizada hibridez. Afincada en la etimología de este último término, la mirada que aquí proponemos intenta reconciliar dos aspectos esenciales: el de las modalidades y formatos textuales, y el de la voz narrativa que los moldea o -mejor dicho, como veremos luego- los fuerza y los socava, estableciendo con ello un diálogo directo con la crónica histórica.

El primer aspecto, marcado por la voz latina hybrida, señala la mezcla de géneros y modalidades enunciativas que vienen a conformar el carácter proteico de la crónica, ya desde sus inicios en nuestro continente, en la época del descubrimiento y la conquista. Hoy, tal como entonces, dentro del mismo texto se mezclan y entrecruzan estrategias narrativas disímiles y complementarias, sin que el objetivo final sea, ni haya sido, necesariamente, lograr homogeneidad o pureza discursiva alguna.

En el caso del narrador que nos ocupa, hemos considerado cuatro de sus libros que cruzan distintos géneros. El primero, Páginas coloniales (2006), integra las modalidades del diario de viajes, el aguafuerte, el cuento, la crónica urbana y -lo que a nuestro parecer resulta más decidor, en tanto revela una lúcida conciencia crítica- la propia tradición cronística de Indias. Si, más allá de su valor descriptivo, aquéllos textos reflejaban el asombro de los descubridores ante el nuevo mundo y las posibilidades que éste les ofrecía, las crónicas de Gumucio traslucen el pasmo desencantado de quien busca en

pasión según Trelew (Tomás Eloy Martínez, 1973), La aventura de Miguel Littin clandestino en Chile (Gabriel García Márquez, 1986); y en Chile: Bomba en una calle de Palermo (Mónica González y Edwin Harrington, 1986), Crimen bajo estado de sitio (María Olivia Mönckeberg y Pamela Jiles, 1986), Asesinato de un periodista (Patricia Collyer y María José Luque, 1987), Los zarpazos del puma (Patricia Verdugo, 1989).

Revista Iberoamericana, Vol. LXXXII, Núm. 254, Enero-Marzo 2016, $185-198$ ISSN 0034-9631 (Impreso)

ISSN 2154-4794 (Electrónico) 
los orígenes una explicación a la propia fatalidad. Porque España, para él, se lee y se escribe como una doble profecía, que sigue pauteando nuestro derrotero republicano; una imagen deformante que nos muestra nuestras propias contradicciones entre ruralismo y posmodernidad: "para mí, un sudaca, Madrid no era sólo una ciudad, era la experiencia de la propia identidad puesta en cuestión en cada esquina, en cada ventanal, en cada estación de metro" (Páginas coloniales 22). Este viaje a la inversa, el viaje a la semilla, supone una pregunta tanto por el origen como por el destino, y asimismo, una enunciación desde esa precariedad. "Vine a España a triunfar" (19), indica un cronista con inevitables ecos rulfianos, y cómo no, si allí tampoco encuentra padre alguno, y la patria, menos que madre, es la "hermana solterona que uno compadece pero necesita, porque guarda en su casa deshabitada y oscura todas las reliquias de la familia" (26).

Ya desde la estrategia comercial de su editorial, que decidió presentarla como una novela, Los platos rotos (2004) continúa la problematización de las convenciones genéricas. Su subtítulo, Historia personal de Chile, establece una relación intertextual explícita con la historiografía -en particular, con el texto de Frías Valenzuela, ${ }^{7}$ según confiesa el autor en el prefacio-, mientras que el epígrafe nos recuerda que la Historia con mayúsculas no es el reflejo fiel de una sucesión cronológica de hechos de relevancia colectiva - como fue la crónica medieval-, sino una fábula convenida (en palabras de Voltaire, que son las que se citan, precisamente, en dicho epígrafe). Dicho en otros términos, los del teórico Hayden White, ${ }^{8}$ se enuncia aquí desde la conciencia de que no existe Historia químicamente pura, sino apenas su relato: se trata de una estrategia narrativa, tropológica, la que estaría asociada a un modo particular de conciencia. La de Gumucio, es fácil deducir, está marcada por la ironía, de lo que resulta un texto escéptico respecto a la posibilidad de alcanzar de modo definitivo el relato del pasado; relativista, en tanto asume la multiplicidad de relatos alternativos de un mismo fenómeno, y profundamente autocrítico.

La narrativización devenida ficcionalización histórica, y exhibida como tal, juega con los criterios de realidad y sus formas enunciativas tradicionales: la carta, la leyenda, el ensayo o la semblanza, e incorpora otras que realzan la cualidad subjetiva de todo relato, como la alegoría, el cuento, el poema, el chiste, el monólogo o el sainete. La desacralización resultante es doble: de un lado horada la solemnidad del discurso historiográfico, revelando su carácter ficticio; del otro, derriba los mitos que aquél ha contribuido a crear. Así, por ejemplo, situado sin conflictos de veridicción en la conciencia de Diego de Almagro, "ese conquistador corriente, sin excentricidad ni luces

7 Francisco Frías Valenzuela escribió el Manual de Historia de Chile desde la Prehistoria, texto de estudio publicado por primera vez en 1986 y que es utilizado hasta el día de hoy como material de estudio básico en colegios y liceos del país.

8 Ver El texto histórico (17-39) y El contenido de la forma (116-122 y 130-135).

Revista Iberoamericana, Vol. LXXXII, Núm. 254, Enero-Marzo 2016, $185-198$ ISSN 0034-9631 (Impreso)

ISSN 2154-4794 (Electrónico) 
ni sombras, feo y tullido, pero simpático" (Platos rotos 19), el cronista lo refiere como lo que es, un personaje de ficción: ${ }^{9}$

¿Para eso viajé tanto - pensó-, para encontrarme desnudo como al principio? Y sintió como una burla el canto de los pájaros, la tierra que hay que trabajar, la lluvia que cae cuando quiere. A la orilla del río Aconcagua, Diego de Almagro recordó con nostalgia fatal el oro que había dejado en el Cuzco, y la ciudad de piedra haciendo equilibrio entre la bruma y la selva. Y tuvo miedo de que este Chile no fuese un territorio sino el fin de su sueño de borracho. (20)

Al nutrirse de textos previamente publicados en periódicos y revistas, ${ }^{10}$ el volumen Monstruos cardinales (2002) aparece mucho más ligado que los anteriores a la actualidad noticiosa y, en consecuencia, la crónica aquí reivindica su filiación periodística antes que histórica. A ello se le suma la crítica de televisión, una serie de cartas abiertas a personajes públicos y, lo que acaso resulte de mayor interés, tres apartados con diseño y tipografía distinta, que bajo el título de "El chileno ilustrado", parodian las entradas de un diccionario. En la línea de Bierce y su Diccionario del diablo, o de Flaubert y el Diccionario de lugares comunes, Gumucio festinea con las miserias mal camufladas de la fauna local, deslizándose en este ejercicio hacia las fronteras de otro modo enunciativo: el aforismo. ${ }^{11}$ Acabando de enturbiar el panorama, en estas entradas, la universalidad de los tópicos se tiñe de episodios autobiográficos, dando paso al tono rector que encontraremos en Memorias prematuras $(1999,2010)$.

La memoria, como modelo canónico que rige la narración de una vida, se reformula para concebirse como un espacio antes que como un género (Arfuch 101-102), donde la hibridez entre formas textuales y visuales viene a dar cuenta de la imposibilidad de dar vida a los recuerdos fuera de la memoria, e incluso de recuperarlos dentro de ella de forma fehaciente. Si la pantalla opera como metáfora del distanciamiento respecto de la propia vida, el texto -al emular la percepción desde aquella- es el rudimentario ensamblaje de escenas para dar la ilusión de una continuidad cronológica regida por un sentido que no existe sino en la gramática de quien lo articula:

9 Usamos el término desde su reformulación desde la historiografía de White, esto es, como la capacidad de una cultura para dotar a los acontecimientos reales de ciertos significados. Ver Metahistory.

${ }^{10}$ Los textos incluidos fueron publicados originalmente en los periódicos Las Últimas Noticias, El Mercurio, La Tercera, El Metropolitano (Chile) y El País (España), y en las revistas APSI, The Clinic y Rock \& Pop (Chile).

11 Por ejemplo: "Los hombres chilenos se agarran a la tierra para no caer; las mujeres se agarran a los hombres para no volar" (Monstruos cardinales 196). "Enero, dieciocho años, nunca has sido más libre y nunca esa libertad ha sido más provisoria, más inútil, más frágil" (186). "El chistólogo debe dar pena para que lo aguantemos. La violencia que el humor desnuda debe ser compensada por la pobre desnudez del cómico arrastrado al escarnio y la piedad del público" (285).

Revista Iberoamericana, Vol. LXXXII, Núm. 254, Enero-Marzo 2016, $185-198$ ISSN 0034-9631 (Impreso)

ISSN 2154-4794 (Electrónico) 
[...] ésta es una de las escenas cumbre, la cámara enfoca la cancha de cemento bajo las nubes gruesas y blancas en el cielo celeste. [...] A lo lejos, en el puerto de Brest, gime un barco langostero. En cualquier otra película tanta tranquilidad, tanto silencio, serían la señal de un bombardeo, de un ataque de los indios o la llegada de un dinosaurio. Aquí no simboliza nada, no espera nada, se detiene. (Memorias prematuras 14 )

En su intervención en el congreso de la Lengua Española celebrado en el año 2007, ${ }^{12}$ el argentino Martín Caparrós se quejaba de la falta de originalidad de los cronistas actuales, que reproducían mecánicamente los hallazgos formales de los padres del new journalism y relegaban la novedad a la búsqueda de personajes excéntricos o situaciones insólitas. Sin embargo, nos parece que la hibridez extrema y autoconsciente de la crónica contemporánea, en general, y la de Rafael Gumucio, en particular, habla por sí misma de una nueva forma de percepción - por tanto, reproduce los modos de aprehensión de una época marcada por la saturación informativa, la que se entreteje en lenguajes múltiples y simultáneos-y de expresión, en tanto da cuenta de la paulatina y al parecer irreversible desaparición de las fronteras genéricas. En ese sentido, la propia estructura de la crónica posmoderna aparece como una suerte de escenificación textual del caos.

El segundo aspecto que nos interesa, el de la conciencia y la voz narrativa, se enraíza en el término griego hybris, que como es sabido, alude a la desmesura del ego y de las pasiones, y que posibilitaba tanto el ascenso como el posterior castigo y caída de los héroes. Más allá de la simple autorreferencia que las narrativas del Yo suponen, la hybris adquiere aquí relevancia analítica en tanto modula la enunciación y la imagen del cronista, que deja de ser sólo un narrador "neutro" para convertirse propiamente en un personaje. Su subjetividad radical, que es tema y filtro de aquello que relata, cuestiona y aniquila la pretendida objetividad referencial de la crónica.

"Soy impune, soy libre, soy aristócrata" (Memorias prematuras 98), se jacta Gumucio, descendiente de políticos ilustres y laureados escritores. Su historia, la historia de su familia, resulta inseparable de la historia de Chile, y esa filiación parece ser suficiente para autorizar y justificar la recurrencia autobiográfica. Su adagio egótico espejea el de uno de los grandes maestros de la crónica, Truman Capote: 'I'm an alcoholic. I'm a drug addict. I'm a homosexual. I'm a genius" (261). Y no sólo en su sintaxis, porque la genialidad, en tanto herencia/yugo familiar y promesa incumplida, será el punto que señale el derrotero de la particular hybris de este cronista:

Yo sería el genio que él [su abuelo Araya] no fue. Sólo tenía que elegir en qué sería un genio. (Memorias prematuras 28)

${ }_{12}$ El texto, titulado "Por la crónica", se reproduce en la Antología de crónica latinoamericana actual, consignada en la bibliografía.

Revista Iberoamericana, Vol. LXXXII, Núm. 254, Enero-Marzo 2016, 185-198 ISSN 0034-9631 (Impreso)

ISSN 2154-4794 (Electrónico) 
Quiero ser un genio o no ser nada, o más bien, tengo miedo de que si no soy un genio puedo llegar a ser nadie (15)

No quiero ser profesor, no quiero ser otra cosa que aquello para lo que me he entrenado interminablemente: genio. Pero no voy a ser eso tampoco, voy a ser un chileno más. Alguien que casi fue un dios y que limpia la parrilla el sábado para invitar a los amigos el domingo. (135)

Si en las crónicas de Indias la hiperbolización lingüística fue la expresión de la maravilla de los descubridores ante la exuberancia del nuevo paisaje, en estos textos se vuelve reflejo de la megalomanía del Yo. "Me gusta usar todas las palabras enormes juntas" (Memorias prematuras 149), reconoce Gumucio, aunque, más que las palabras en sí, lo que realmente caracterizará su estilo personal será el tono enunciativo. Éste, comprendido como la "inflexión de la voz y modo particular de decir algo" (RAE), está determinado por, al menos, tres factores: el estado de ánimo de quien enuncia, su intención comunicativa, y las convenciones genéricas del texto que produce.

Lo que aquí encontramos es una voz que, marcada por la rabia, la frustración y acaso el odio, configura una suerte de grito; el gesto impotente de quien ha sido expulsado del Olimpo y chilla al cielo con los puños cerrados. "Yo no perdono. Quizá cuando deje de escribir estas páginas, pero no ahora" (Memorias prematuras 22-23), advierte, convirtiendo su texto en la arena donde ajusta cuentas con la Historia -la personal y la colectiva-; con sus figuras y sus mitos rectores: "Me desnudo de algunas de esas mentiras que este país me obligó a vestir para no andar indefenso por el Paseo Ahumada, ni rabio, ni juzgo, ni moralizo, sólo digo mi nombre con todos los apellidos que esta historia, sin héroes ni moraleja, me ha puesto encima" (Monstruos cardinales 16).

Desde esta particularidad enunciativa, la narración adquiere una función que podríamos considerar psicoanalítica, en virtud de la cual el cronista vuelve al pasado en busca de aquellos episodios traumáticos que pueden explicar la parábola del fracaso. El golpe de Estado y Pinochet, la separación de los padres, la dislexia, don Francisco monopolizando la tarde del sábado desde el televisor, los terremotos, el exilio, son pruebas que Gumucio acumula y exhibe en busca de su propia exculpación. "La dictadura me hizo así" (Monstruos cardinales 27), reza el título de una de sus crónicas. O, como señala, aún más explícitamente, en otro libro: "Si, como dicen los psiquiatras, el rol del padre es separar al niño de la inconsciencia y lanzarlo al mundo, yo soy hijo de Pinochet" (Platos rotos 135). Pinochet, padre déspota de la horda primitiva, muere y deja a sus vástagos huérfanos, condenados a vagar por una infancia donde se enraíza y crece el daño, del que únicamente se tomará conciencia a posteriori. Así entendemos la recurrente identificación del narrador con un niño, que aterrorizado ante el imperativo de hacerse adulto, se escuda en la megalomanía y en el delirio de genialidad. Su escritura, antes que todo, da cuenta del choque entre esa conciencia individual y el mundo:

Revista Iberoamericana, Vol. LXXXII, Núm. 254, Enero-Marzo 2016, 185-198 ISSN 0034-9631 (Impreso)

ISSN 2154-4794 (Electrónico) 


\begin{abstract}
Atravieso los años, estudio sin estudiar, todos los años se repite mi promedio 5,5, paso a duras penas la universidad, sigo tratando de impresionar a cualquier precio, sigo gritando y rogando, sigo, con una timidez infernal, gritando a quien quiera escucharme. Hago lo posible para que me amen, tartamudeo y hablo por radio y televisión, no sé escribir dos palabras sin una falta de ortografía y escribo en los diarios, en las revistas, en los libros, todo por impresionar. (Memorias prematuras 30)
\end{abstract}

El tono, entonces, al ser "la materialización física de un afecto manifestado a través de los signos de un determinado código" (Spang 392) viene a singularizar la voz narrativa, mostrándonos al cronista como un personaje dotado de psicología, historia e intención. En su desmesura enunciativa, el tono de Gumucio -irónico, sarcástico, doliente e incluso autoflagelante-refleja tanto la intensidad de las pasiones que animan su escritura (pathos), como la insubordinación a las reglas y las fronteras genéricas, y en ese sentido el tono condensa el descontrol inherente a toda hybris. Resulta elocuente, entonces, que Gumucio se defina como un cronista que "ensucia lo que toca y deja sobre las paredes manchones, gestos y brochazos" (Platos rotos 177). Al exhibir las costuras y marcas de fábrica de su crónica, fuerza las convenciones de este "género" y nos obliga a repensar sus elementos constitutivos en el momento presente.

En este ejercicio, los textos de Gumucio deben insertarse dentro de la tradición cronística con la cual dialogan de forma directa. La hibridez y el peso radical de la voz narrativa que hemos revisado se revelan, entonces, no como una novedad propia de la época posmoderna, sino como una herencia de los escritos del descubrimiento. Porque ya esas crónicas, relaciones y cartas, como notó Walter Mignolo en uno de sus textos más influyentes, ${ }^{13}$ presentan distintas estrategias de desajuste a las formaciones textuales y los tipos discursivos, configurando así piezas ambiguas e históricamente innovadoras. A eso se le suma la fuerte influencia de las lecturas previas -como la Geografía de Ptolomeo, o la Historia natural de Plinio- en la concepción de mundo de los primeros cronistas; influencia que explicaría en gran parte la "ficcionalización distorsionadora" de la realidad que cruza sus escritos (Pastor 37). Y, por último, está el asunto de la posición e intencionalidad de los autores, que contaminaron la función referencial de sus crónicas, otorgándoles con ello un tono característico: el mitificador, el del fracaso, el de la rebeldía (Pastor 79). En fin, como bien resume Mercedes Serna:

Las crónicas indianas son una mezcla de autobiografía, testimonio ajeno, observación de la realidad y amor por las cosas, evangelización, sorpresa ante los ritos y creencias, admiración por el heroísmo propio y por la conducta ajena. Nacen por la necesidad de contar lo insólito y lo nunca visto, de la disputa entre otros conquistadores, de la

13 Ver Mignolo, “Cartas, crónicas” (57-59 y 70-71).

Revista Iberoamericana, Vol. LXXXII, Núm. 254, Enero-Marzo 2016, 185-198 ISSN 0034-9631 (Impreso)

ISSN 2154-4794 (Electrónico) 
nostalgia del pasado, de la búsqueda de la fama, del honor, o la retribución esperada. En cualquier caso, las crónicas reflejan la psicología del autor. (56)

O, en palabras de nuestro cronista:

Ercilla será el antecedente español para una larga genealogía de mitómanos chilenos. El mentiroso insigne que habla de una tierra que nadie conoce, y que fabrica según los deseos de sus oyentes. Épica demente en Ercilla, surrealismo indigenista en Roberto Matta, selva primordial y melancólica en Neruda, realismo a lo mágico de Isabel Allende. (Platos rotos 26)

Podríamos aventurar, entonces, que la singularidad de la crónica de Rafael Gumucio radica en la voluntad de establecerse como contratexto de aquellos escritos históricos, problematizando en su parodia, las relaciones y fronteras canónicas que se han establecido desde entonces entre historia y literatura, verdad y ficción, objetividad y subjetividad, autor y narrador. Desde aquí, se abre una reflexión que en última instancia apuntaría al estatuto ontológico de la narrativa, y que -según el crítico Ernesto Laclau (15) - convoca al psicoanálisis, cuyo discurso estaría a la base de toda la re-teorización contemporánea del sujeto; la deconstrucción de géneros y cánones, que develaría nuevas áreas indecidibles en la estructuración de la objetividad, y la retórica, que lejos de ser mero adorno del lenguaje, pasa a ser comprendida como campo primario de la construcción de la realidad. El sentido, a partir de estas crónicas y retomando la ya citada concepción de White, se concibe y se revela como efecto de una gramática, no de los hechos que ésta articula. Y explica, no sólo aquello que refiere, sino también y sobre todo, nuestra propia forma de aprehenderlo. Como bien indica Gumucio: "Cuento lo que soy para que sepan lo que no voy a contar" (Platos rotos 114$).{ }^{14}$

Si en sus escritos, Colón -que murió convencido de que había llegado a las Indiasprocuró adaptar la realidad que veía a lo que debía ser, según sus necesidades y sus lecturas medievales; hoy la prosa de Gumucio configura una diatriba rabiosa contra esa realidad que se niega a amoldarse a sus deseos. Entre ambos, el nuevo mundo se hizo viejo, y el texto que otrora narraba sus maravillas se convirtió en la crónica de su desencanto. O incluso, como señala este autor en la carta a Nicanor Parra que abre Los platos rotos: "ese Chile que usted aún habita, del cual es no sólo el sobreviviente sino el único viviente, ese Chile a mí me tocó muerto. Déjeme, a mí, que no lo conocí, escribir su epitafio" (14).

Un epitafio. Y acaso esta no resulte ser, a fin de cuentas, la última y más reciente hibridación textual de la crónica.

14 En cursivas en el original.

Revista Iberoamericana, Vol. LXXXII, Núm. 254, Enero-Marzo 2016, 185-198 ISSN 0034-9631 (Impreso)

ISSN 2154-4794 (Electrónico) 


\section{BiBLIOGRAFÍA}

Aguilera, Octavio. La literatura en el periodismo y otros estudios en torno a la libertad y el mensaje informativo. Madrid: Paraninfo, 1992.

Arfuch, Leonor. El espacio biográfico. Dilemas de la subjetividad contemporánea. Buenos Aires: FCE, 2010.

Borrat, Héctor: El periódico, actor político. Barcelona: Gustavo Gili, 1989.

Caparrós, Martín. "Por la crónica". Antología de crónica latinoamericana actual. Darío Jaramillo Agudelo, ed. Madrid: Alfaguara, 2012. 607-612.

Capote, Truman. "Nocturnal Turnings, or How Siamese Twins Have Sex." Music for Chamaleons. Nueva York: Vintage Books, 1994. 243-262.

Chillón, Lluís Albert y Manuel Vázquez Montalbán. Literatura y periodismo. Una tradición de relaciones promiscuas. Barcelona: Universitat Autònoma de BarcelonaUniversitat Jaume I-Universitat de València, 1999.

"Crónica periodística latinoamericana comienza a ganarle en prestigio al cuento y la novela". Cambio. <http://www.cambio.com.co/culturacambio/840/ARTICULOWEB-NOTA_INTERIOR_CAMBIO-5783627.html>. 1 abril 2011.

Fundación Gabriel García Márquez para el Nuevo Periodismo Iberoamericano. <www. fnpi.org >. 28 marzo 2011.

GonzálezEchevarría, Roberto. Mito y archivo. Una teoría de la narrativa latinoamericana. México: FCE, 2000.

Grijelmo, Álex. El estilo del periodista. Madrid: Taurus, 2001.

Gumucio, Rafael. Páginas coloniales. Buenos Aires: Mondadori, 2006. Los platos rotos. Una historia personal de Chile. Santiago de Chile: Sudamericana, 2004.

Memorias prematuras. Santiago de Chile: Random House, 2010. Monstruos cardinales. Santiago de Chile: Sudamericana, 2002.

Gutiérrez Palacio, Juan. Periodismo de opinión. Redacción periodística, editorial, columna, artículo, crítica, selección de textos. Madrid: Paraninfo, 1984.

Hernando Cuadrado, Luis Alberto. El discurso periodístico. Madrid: Editorial Verbum, 2000.

Iñigo Madrigal, Luis, coord. Historia de la literatura hispanoamericana. Tomo I. Época colonial. Madrid: Cátedra, 1982.

Jaramillo Agudelo, Darío, ed. Antología de la crónica latinoamericana actual. Madrid: Alfaguara, 2012.

Laclau, Ernesto. Introducción. El espacio biográfico. Dilemas de la subjetividad contemporánea. Leonor Arfuch, ed. Buenos Aires: FCE, 2010. 11-15.

"Los nuevos cronistas". Capital 197 (26 enero 2007). < http://www.capital.cl/reportajesy-entrevistas/los-nuevos-cronistas-singulares-e-insolentes-observado.html $>$. 1 abril 2011.

Revista Iberoamericana, Vol. LXXXII, Núm. 254, Enero-Marzo 2016, $185-198$ ISSN 0034-9631 (Impreso)

ISSN 2154-4794 (Electrónico) 
Martín Vivaldi, Gonzalo. Géneros Periodísticos. Madrid: Paraninfo, 1973.

Martínez Albertos, José Luis. Curso general de redacción periodística. Periodismo en prensa, radio, televisión. Barcelona: Mitre, 1983.

Martínez Vallvey, Fernando. Herramientas periodísticas. Salamanca: Librería Cervantes, 1996.

Matute, Álvaro. “Crónica: historia o literatura”. HMex XLVI/4 (1996): 711-722.

Mignolo, Walter. "Cartas, crónicas y relaciones del descubrimiento y la conquista". Historia de la literatura hispanoamericana. Tomo I. Época Colonial. Luis Iñigo Madrigal, coord. Madrid: Cátedra, 1982. 57-102.

"El metatexto historiográfico y la historiografía indiana". Modern Language Notes 96 (1981): 358-402.

Monsiváis, Carlos. "De la hora del ángelus a la del zapping. La crónica en América Latina”. Letras Libres (2005): 50-58.

Morales Toro, Leonidas. "Joaquín Edwards Bello: crónica y crítica de la vida cotidiana chilena". Revista Chilena de Literatura 74 (abril 2009): 57-78.

Ossandón, Carlos. El crepúsculo de los sabios y la irrupción de los publicistas. Prensa y espacio público en Chile (siglo XIX). Santiago de Chile: Lom/Universidad ARCIS, 1998.

y Eduardo Santa Cruz. Entre las alas y el plomo. La gestación de la prensa moderna en Chile. Santiago de Chile: Lom/Univeraidad ARCIS, 2001.

Pastor, Beatriz. El discurso narrativo de la conquista de América. La Habana: Casa de las Américas, 1983.

Paz, Octavio. El laberinto de la soledad. Madrid: Cátedra, 2001.

Rama, Ángel. Rubén Darío y el Modernismo, (circunstancia socioeconómica de un arte americano). Caracas: Universidad Central de Venezuela, 1970.

Ramos, Julio. Desencuentros de la Modernidad en América Latina. Literatura y política en el siglo XIX. México: FCE, 1989.

RealAcademia Española. Diccionario de la lengua española. Madrid: Espasa Calpe, 2001.

Rivas, Matías. "Chile según sus cronistas”. La Tercera. 18 sept. 2009: sección Opinión. $<$ http://latercera.com/contenido/661_183306_9.shtml>. 1 abril 2001.

Rotker, Susana. La invención de la crónica. México: FCE-Fundación para un Nuevo Periodismo Iberoamericano, 2005.

Serna, Mercedes, comp. y ed. Crónicas de Indias. Antología. Madrid: Cátedra, 2009.

Spang, Kurt. "Acerca de los tonos en la literatura". Revista de Literatura LXVIII/136 (Julio-Diciembre 2006): 387-404.

Todorov, Tzvetan. "El origen de los géneros”. Teoría de los géneros literarios. Miguel Ángel Garido Gallardo, comp. Madrid: Arco/Libros, 1988. 31-48.

Vilamor, José R. Redacción periodística para la generación digital.Los grandes cambios técnicos, económicos y culturales exigen profundas trasformaciones en el campo del periodismo. Madrid: Universitas, 2000.

Revista Iberoamericana, Vol. LXXXII, Núm. 254, Enero-Marzo 2016, 185-198 ISSN 0034-9631 (Impreso)

ISSN 2154-4794 (Electrónico) 
White, Hayden. El texto histórico como artefacto literario y otros escritos. Barcelona: Paidós, 2003.

El contenido de la forma. Narrativa, discurso y representación histórica. Barcelona: Paidós, 1992.

Metahistory: The Historical Immagination in Nineteenth-Century Europe. Baltimore y Londres: Johns Hopkins UP, 1973.

Wolfe, Tom. El nuevo periodismo. Barcelona: Anagrama, 1976.

Yanes Mesa, Rafael. "La crónica, un género del periodismo literario equidistante entre la información y la interpretación". Espéculo 32 (marzo-junio 2006). <http://www. ucm.es/info/especulo/numero32/cronica.html>. 4 enero 2011. 